\title{
The freeze/thaw process and the surface energy budget of the seasonally frozen ground in the source region of the Yellow River
}

\author{
Jingyuan Wang ${ }^{1,2} \cdot$ Siqiong Luo ${ }^{1}$ (D) $\cdot{\text { Zhaoguo } \mathrm{Li}^{1} \cdot \text { Shaoying Wang }}^{1} \cdot{\text { Zhenhua } \mathrm{Li}^{3}}^{3}$
}

Received: 13 February 2019 / Accepted: 30 May 2019 / Published online: 22 June 2019

(C) The Author(s) 2019

\begin{abstract}
The freeze/thaw process and the surface energy budget of the seasonally frozen ground in the source region of the Yellow River were investigated by using observed soil temperature and moisture and the energy flux from May 12, 2014, to May 11, 2015. Compared with the Maduo site, the starting date of the freezing process was later and the freezing depth was shallower at Maqu site. The maximum frozen depth was about $320 \mathrm{~cm}$ at Maduo site and $90 \mathrm{~cm}$ at Maqu site. The soil temperature of Maqu site was higher than of Maduo site due to lower latitude and altitude. The soil was the driest under the depth of $40 \mathrm{~cm}$ and $80 \mathrm{~cm}$ at Maduo and Maqu sites, respectively. The diurnal amplitudes of soil temperature of Maduo site were larger than of Maqu site at four freeze/thaw stages; the amplitudes were the largest in the completely thawed stage $\left(9.19{ }^{\circ} \mathrm{C}\right.$ and $\left.4.35{ }^{\circ} \mathrm{C}\right)$ and minimal in the freezing stage $\left(1.23^{\circ} \mathrm{C}\right.$ and $\left.0.47^{\circ} \mathrm{C}\right)$. The diurnal amplitudes of soil moisture of Maqu site were greater than of Maduo site at all stages. The net radiation Rn's seasonal change was hardly influenced by the freeze/thaw process. The mean ground heat flux $\left(\mathrm{G}_{0}\right)$ was negative during the freezing and completely frozen stage and positive during the thawing and completely thawed stage. During the completely thawed and frozen stages, the latent heat flux (LE) and sensible heat flux (H) predominated in the surface energy distribution, respectively. Overall, the variations of fluxes were affected by both the monsoon and freeze/thaw process of the soil layer in seasonally frozen region. The freeze/thaw process had a significant effect on the diurnal change of $\mathrm{G}_{0}$ during the freezing stage. The annual energy closure status of Maduo and Maqu sites was 0.77 and 0.58 , respectively. The energy closure status was the highest during the completely thawed stage at Maduo site and during the thawing stage at Maqu site and lowest during the freezing stage among the four stages, due to the snow cover's impact. Overall, the freeze/thaw process and the high albedo caused by snow cover had effects on the energy closure status.
\end{abstract}

\section{Introduction}

The Tibetan Plateau (TP), is the largest and most extensive plateau of the world, is known as "the roof of the world" (Ma et al. 2005; Qiu 2008; Wu et al. 2012). The water and energy

Siqiong Luo

1sq@1zb.ac.cn

1 Key Laboratory of Land Surface Process and Climate Change in Cold and Arid Regions, Northwest Institute of Eco-Environment and Resources, Chinese Academy of Sciences, Lanzhou 730000, China

2 University of Chinese Academy of Sciences, Beijing 100049, China

3 Global Institute for Water Security, University of Saskatchewan, Saskatoon S7N 3H5, Canada cycle over the TP have far-reaching impacts on the Asian climate system's formation and evolution and is one of the important parts of the global water and energy cycle (Webster 1987). Seasonally frozen grounds are widely present in the TP, with the area of $1.46 \times 10^{6} \mathrm{~km}^{2}$ over the TP (Zou et al. 2017). Because of its effects on water supplies (Guo et al. 2011a), energy exchanges ( $\mathrm{Gu}$ et al. 2015), and climatecryosphere interactions in the atmospheric boundary layer (Chen et al. 2008), seasonally frozen soil becomes an important portion of hydrologic and climatic variables (Duguay et al. 2013; Gu et al. 2015).

On the northeastern TP lies the source region of the Yellow River Basin, where the land surface covers from transitional, mosaicked zones of seasonally frozen ground and isolated patched permafrost to discontinuous and continuous permafrost (Jin et al. 2010). In recent years, due to the extreme sensitivity of the source region of the Yellow River to the 
climate change, a series of ecological and environmental degradation phenomena ensue: the cutoff of the main river, accelerated melting of glaciers, and thinning of frozen ground layer (Hu et al. 2011; Lan et al. 2010; Li et al. 2013; Ye et al. 2015). The trends of air temperature and soil temperature and the parameters of seasonally frozen ground and permafrost have been studied in the source region of the Yellow River by many recent studies (Hu et al. 2012; Jin et al. 2009, 2010; Li et al. 2013; Ye et al. 2015). One recent study has found that the warming trend of the soil in the region is greater than in the other parts of the TP (Luo et al. 2016). Significant warming trends have been observed in this region over the periods 1960-1990, 1960-2000, and 1960-2006, particularly over the period 1960-2006 (Hu et al. 2012). Jin et al. discovered the mean rate of air temperature rise of the source area of the Yellow River was $0.02{ }^{\circ} \mathrm{C}_{\text {year }}{ }^{-1}$ since the 1980 s (Jin et al. 2009). Significant soil warming was detected, and the warming trend of soil was greater than of the air. During 1981-2014, the temperatures of surface soil $(0 \mathrm{~cm})$, shallow layer soil $(5-20 \mathrm{~cm})$, and deep layer soil $(40-320 \mathrm{~cm})$ had been risen at rates of $0.706{ }^{\circ} \mathrm{C}, 0.477{ }^{\circ} \mathrm{C}$, and $0.417{ }^{\circ} \mathrm{C}$ decade $^{-1}$ in three river source regions (Luo et al. 2016).

The soil freeze/thaw cycle is very sensitive to climate change, especially in the near-surface soil (Guo and Wang 2013; Yang et al. 2007). In recent years, significant warming of the source region of Yellow River unavoidably leads to changes in the soil freeze/thaw cycles (Guo and Wang 2014; $\mathrm{Li}$ et al. 2002). These warming trends caused an increase in the thickness of permafrost active layer, a decrease of the frozen depth of seasonally frozen ground, a delay of the freeze first date, a significant advance of the freeze last date, and an accelerated decrease of the freeze duration (Guo and Wang 2013; Guo and Wang 2014; Li et al. 2012; Luo et al. 2017; Wang et al. 2015; Wu et al. 2012; Xian et al. 2009; Zhao et al. 2010). Since the 1980s, the average maximum depth of frost penetration has decreased by $0.1-0.2 \mathrm{~m}$ in the source region of Yellow River, and the maximum frozen depths of seasonally frozen ground vary from 2.2 to $2.4 \mathrm{~m}$ in the Maduo weather station (Jin et al. 2009). According to a recent study, the freeze duration experienced an accelerated decrease during the 1960-2014, 1985-2014, and 2000-2014 periods, and the rate of decrease was -7.52 days decade ${ }^{-1}$ over the past 55 years, -14.74 days decade ${ }^{-1}$ over the past 30 years, and -16.90 days decade $^{-1}$ over the past 15 years (Luo et al. 2017).

Traditionally, the processes of soil thawing and freezing are accompanied by frequent phase transitions between soil ice and soil water, resulting in the absorption and release of latent heat. The oscillation in the soil thermal regime and the corresponding freeze/thaw cycles cause changes in the exchanges of energy and moisture between surface soil and atmosphere (Guo et al. 2011a; Yang et al. 2007). Because the soil freeze/ thaw processes change the sensible and latent heat flux, radiant flux, energy and momentum exchange between the surface and atmosphere via the change of the surface albedo, evapotranspiration, the soil infiltration, runoff, and the condition of vegetation, the soil freeze/thaw processes have an extensive impact on climate change (Chen et al. 2014). The importance of soil freeze/thaw processes on the land surface-atmosphere exchange has been highlighted by several recent studies on the TP. The spatiotemporal variations in surface water and the heat balance are caused by the land surface seasonal freeze/ thaw processes and their spatial distribution in both observation and model simulation (Guo et al. 2011b). Data observed at the Tanggula and Xidatan monitoring stations indicates that a seasonal alternation was exhibited between the latent heat flux (LE) and the sensible heat flux (H), and the characteristic primarily depends on the freeze/thaw processes of the active layer and monsoon precipitation (Yao et al. 2011).

According to the simulation experiments by Chen et al. (Chen et al. 2014), the freeze/thaw process has a buffering influence on the seasonal changes of soil and near-surface temperatures and reinforces the energy exchange between the surface soil and the atmosphere. Therefore, the effects of freezing and thawing process of seasonally frozen ground on the surface energy budget of the source region of the Yellow River must be included to represent their impacts on the landatmosphere interactions.

The main purpose of this study is to reveal the details of the freeze/thaw process and the surface energy budget of the seasonally frozen ground in the source region of the Yellow River through observation data. The annual and daily changes of soil temperature, soil moisture, and surface energy flux with different freeze/thaw stages were analyzed by using observation data from the Maduo and Maqu sites from May 12, 2014, to May 11, 2015. The start and end time of each freeze/thaw stage were determined by a new method. Section 2 presents the description of data and methods. In section 3, we show the results of analysis and we discussed them in the context of flux exchange between the soil and the atmosphere.

\section{Data and methods}

\subsection{Sites and data}

The basic data used in this study were obtained at two monitoring sites. These two sites are located in the northwest (Maduo site) and southeast (Maqu site) of the source region of the Yellow River, respectively (Fig. 1). The Maduo site $\left(97^{\circ}\right.$ $34^{\prime} \mathrm{E}, 34^{\circ} 54^{\prime} \mathrm{N}$; and $4280 \mathrm{~m}$ ) is located on the alpine steppe of the west bank of Lake Ngoring, within the plateau subfrigid semi-arid climate zone. The Maqu site $\left(102^{\circ} 09^{\prime} \mathrm{E}, 33^{\circ} 53^{\prime} \mathrm{N}\right.$; and $3423 \mathrm{~m}$ ) is located in a relatively large open space. The climate zone of this site is plateau subfrigid humid (Zheng et al. 2010). The total vegetation coverage is about $92 \%$ with alpine meadow, and the heights of the grass in the summer and 
Fig. 1 Geographic location of the Maduo and Maqu sites

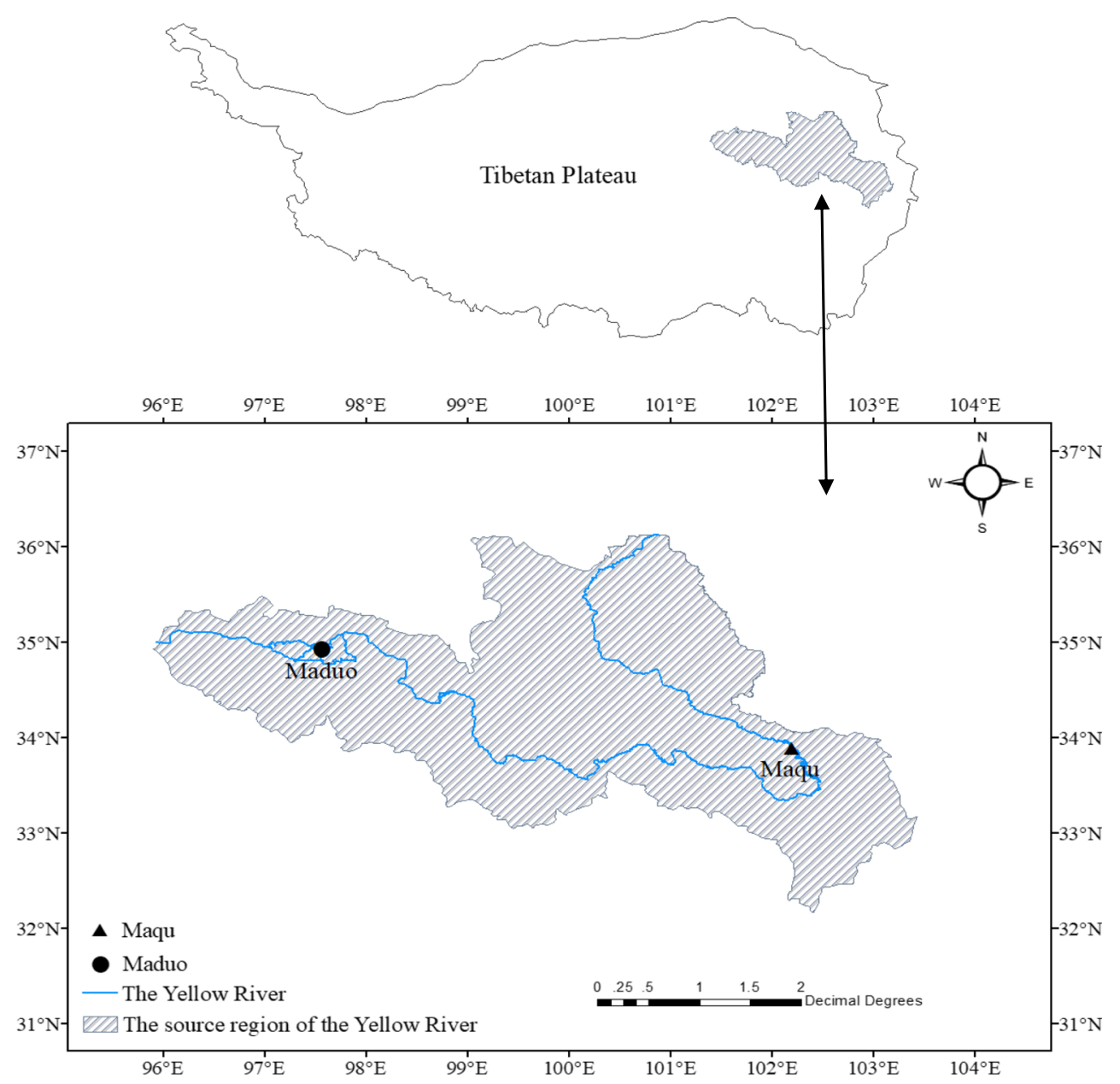

winter are about $15 \mathrm{~cm}$ and $5 \mathrm{~cm}$, respectively. According to the soil temperature data of the two sites as shown in Fig. 2, Maduo site and Maqu site are both located within the seasonally frozen soil region. Though the surface is mainly covered with sandy and loam soil at both sites, the soil at Maduo site contains substantial amount of gravel and fine stone, and its soil particle size is coarser than that at Maqu site. According to the dataset of annual surface observation values of China provided by the China Meteorological Data Service Center (CMDC), the average annual air temperature at the Maduo
Fig. 2 The isotherms of the soil temperature at Maduo (a) and Maqu (b) site from May 12, 2014, to May 11,2015 . The isotherm intervals are $2{ }^{\circ} \mathrm{C}$
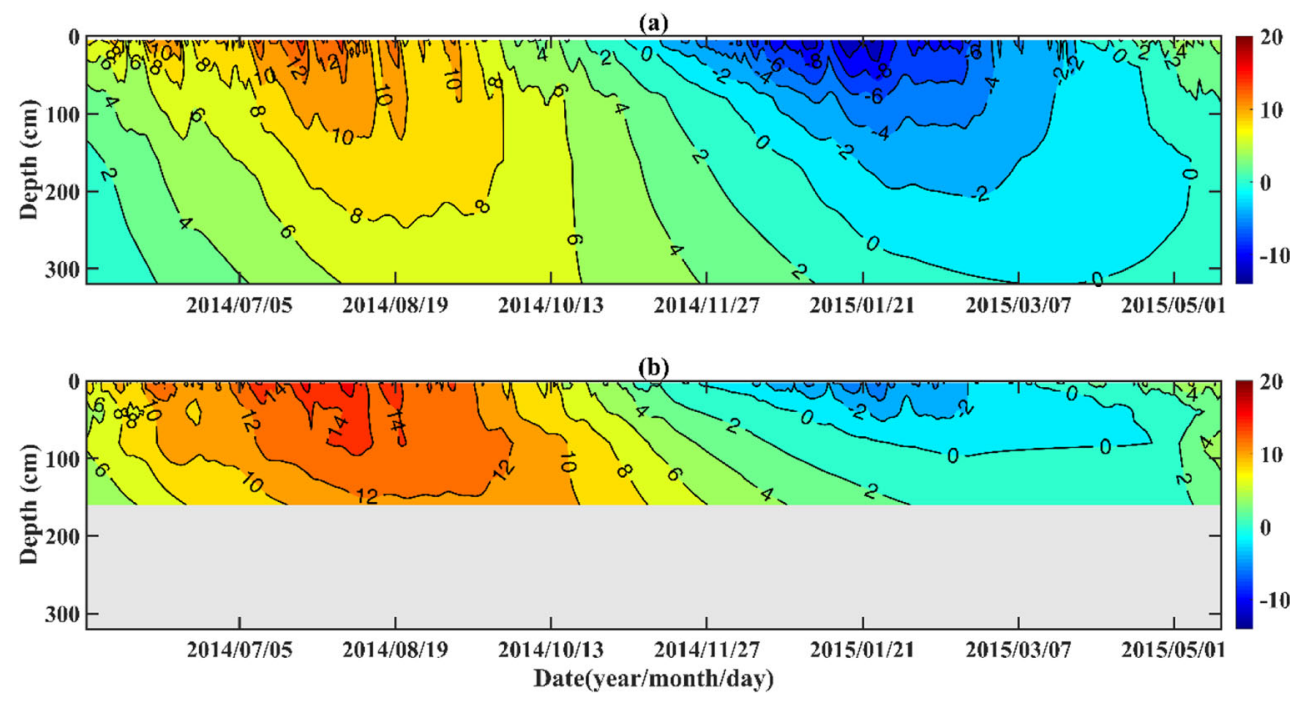
and Maqu sites was $-3.3^{\circ} \mathrm{C}$ and $1.8^{\circ} \mathrm{C}$, respectively, and the average annual precipitation (1981-2010) was $332.5 \mathrm{~mm}$ and $593.4 \mathrm{~mm}$, respectively.

The data used in this work were primarily observed from micrometeorological gradient towers and eddy covariance system at the Maduo and Maqu sites from May 12, 2014, to May 11, 2015 (Beijing time). The Maduo observation system is composed of a grass station and a gradient tower station. The grass station was located about $1500 \mathrm{~m}$ to the western lakeshore. The sensible heat flux $(\mathrm{H})$ and latent heat flux (LE) were obtained from an eddy covariance system of the grass station, which primarily included a 3-D ultrasonic anemometer (CSAT3, Campbell Scientific) and an open path fast response CO2/H2O infrared gas analyzer (LI-7500/EC150, LICOR/Campbell Scientific). The system was located at $3.2 \mathrm{~m}$ above the ground surface and can be used to measure the 3-D wind velocity, the density of water vapor, and $\mathrm{CO}_{2}$. The downward and upward shortwave and longwave radiation were measured by a four-component net radiometer (CNR-1, Kipp and Zonen) at $1.5 \mathrm{~m}$ height (Li et al. 2015). These data were recorded with a data logger (CR3000, Campbell Scientific). The tower station was located about $30 \mathrm{~m}$ to the lakeshore; the soil temperature and the soil moisture content were recorded at the depths of $0.05,0.10,0.20,0.40,0.80$, 1.60 , and $3.20 \mathrm{~m}$ at the tower station (109L, Campbell Scientific) with a CR1000 data logger (Campbell Scientific). The soil temperature and the soil moisture content of the tower station and other data of the grass station were used in this study. The Maqu site included an eddy covariance system and micrometeorological measurements. The component parts of the eddy covariance system of Maqu site were the same as that of Maduo site. The system consisted of a 3-D ultrasonic anemometer (CSAT-3, Campbell Scientific) and an open path infrared gas analyzer (LI-7500/EC150, LI-COR/Campbell Scientific). Net radiation ( $\mathrm{Rn}$ ) was measured by a net radiometer (CNR-1, Kipp and Zonen) at $1.5 \mathrm{~m}$ above the soil surface (Shang et al. 2015). Soil temperature and soil moisture water content were observed at the depths of $0.025,0.05,0.10,0.20$, $0.40,0.80$, and $1.60 \mathrm{~m}$ at Maqu site. Soil heat flux $\left(\mathrm{G}_{0}\right)$ was obtained using heat flux plates (HPF01, Wohlwend Engineering) at a depth of $0.07 \mathrm{~m}$ below the soil surface. Table 1 shows the height or depth of the instruments related to the study at Maduo and Maqu site.

\subsection{Methods}

\subsubsection{Ground heat flux}

The ground surface heat flux $\left(\mathrm{G}_{0}\right)$ can be measured by the heat flux plate directly except for rare cases. The position of the heat flux plate usually has a certain depth (Heusinkveld et al. 2004). Therefore, $\mathrm{G}_{0}$ was usually calculated by the 1 -D soil heat conduction equation (Falge et al. 2001; Liebethal et al. 2005):

$G_{0}=G(Z)+C_{V} \int_{0}^{Z} \frac{\partial T(z)}{\partial t} d z$

The first term on the right side of the equation is the soil heat flux at a depth of $Z$, and the second term is the soil heat flux between the ground and the depth of $Z$ over time. Since the depths of the measured soil heat flux at two sites are different, integrating Eq. (1), we obtain:

$$
\begin{aligned}
G_{0}= & G_{5 \mathrm{~cm}}+C_{v} \\
& \times\left(0.025 \times \frac{\partial T_{0 \mathrm{~cm}}}{\partial t}+0.025 \times \frac{\partial T_{2.5 \mathrm{~cm}}}{\partial t}\right) \\
G_{0}= & G_{7.5 \mathrm{~cm}}+C_{v} \\
& \times\left(0.025 \times \frac{\partial T_{2.5 \mathrm{~cm}}}{\partial t}+0.05 \times \frac{\partial T_{5 \mathrm{~cm}}}{\partial t}\right)
\end{aligned}
$$

Table 1 Height or depth of the instruments related to the study at Maduo and Maqu sites

\begin{tabular}{llll}
\hline & Observation item & Instruments & Height/depth \\
\hline Maduo & 3-D wind velocity & CSAT3 & $3.20 \mathrm{~m}$ \\
& Soil heat flux & HPF01 & $5,20 \mathrm{~cm}$ \\
& Radiant components & CNR-1 & $1.50 \mathrm{~m}$ \\
& Soil temperature & $109 \mathrm{~L}$ & $5,10,20,40,80,160,320 \mathrm{~cm}$ \\
& Soil moisture content & CS616 & $5,10,20,40,80,160,320 \mathrm{~cm}$ \\
Maqu & Land surface temperature & SI-111 & $0 \mathrm{~m}$ \\
& 3-D wind velocity & CSAT3 & $3.20 \mathrm{~m}$ \\
& Soil heat flux & HPF01 & $7.5 \mathrm{~cm}$ \\
& Radiant components & CNR-1 & $1.50 \mathrm{~m}$ \\
& Soil temperature & $107 \mathrm{~L}$ & $2.5,5,10,20,40,80,160 \mathrm{~cm}$ \\
& Soil moisture content & CS616 & $2.5,5,10,20,40,80,160 \mathrm{~cm}$ \\
\hline
\end{tabular}


where the ground surface heat flux $\mathrm{G}_{0}$ of the Maduo and Maqu sites is obtained by Eq. (2) and Eq. (3). The average volume heat capacity $\left(c_{v}\right)$ is defined as:

$C_{v}=C_{\mathrm{dry}}+C_{\mathrm{liq}} \theta_{Z}$

where $C_{\mathrm{dry}}=0.90 \times 10^{6} \mathrm{~J} / \mathrm{m}^{3} \cdot \mathrm{K}$ is the volume heat capacity of dry soil, $C_{\text {liq }}=4.18 \times 10^{6} \mathrm{~J} / \mathrm{m}^{3} \cdot \mathrm{K}$ is the volume heat capacity of liquid water, $\theta_{Z}$ is the soil moisture content $(\%)$ at a depth of $Z, G_{Z}$ is the observed soil heat flux $\left(\mathrm{W} / \mathrm{m}^{2}\right)$ at a depth of $Z$, and $T(Z)$ is the soil temperature at a depth of $Z$.

\subsubsection{Net radiation}

The net radiation $(\mathrm{Rn})$ was estimated from the four radiant components of the two sites according to the following equation:

$\mathrm{Rn}=R l_{\text {downwell }}-R l_{\text {upwell }}+R s_{\text {downwell }}-R s_{\text {upwell }}$

where $R l_{\text {downwell }}$ is the downward longwave radiation $\left(\mathrm{W} / \mathrm{m}^{2}\right)$, $R l_{\text {upwell }}$ is the upward longwave radiation $\left(\mathrm{W} / \mathrm{m}^{2}\right), R s_{\text {downwell }}$ is the downward shortwave radiation $\left(\mathrm{W} / \mathrm{m}^{2}\right)$, and $R s_{\text {upwell }}$ is the upward shortwave radiation $\left(\mathrm{W} / \mathrm{m}^{2}\right)$.

\subsubsection{Sensible heat flux and latent heat flux}

The sensible heat flux $(\mathrm{H})$ and the latent heat flux (LE) are obtained by 30 -min mean covariance:

$$
\begin{aligned}
& \mathrm{H}=\rho_{a} c_{p} \overline{w^{\prime} T^{\prime}} \\
& \mathrm{LE}=L_{v} \rho_{a} \overline{w^{\prime} q^{\prime}}
\end{aligned}
$$

where $\rho_{a}$ is the atmospheric density $\left(\mathrm{kg} \mathrm{m}^{-3}\right), c_{p}$ is the specific heat capacity of the atmosphere at the constant pressure $(\mathrm{J} / \mathrm{kg} \cdot \mathrm{K}), w$ is the velocity of the vertical wind $(\mathrm{m} / \mathrm{s}), T$ is the air temperature $(\mathrm{K}), L_{v}$ is the latent heat of vaporization $\left(\mathrm{W} / \mathrm{m}^{2}\right)$, and $q$ is the specific humidity of air $(\mathrm{kg} / \mathrm{kg})$.

It is an unavoidable and universal problem to encounter missing data for a long-term continuous observation because of power failure or instrument malfunction. Moreover, the data quality control may increase data gaps of the data sets because of the elimination of unreasonable data (Shang et al. 2015). For the data mentioned above, the mean diurnal variation (MDV) method could be used to fill the data gaps. The mean diurnal variation (MDV) method is a technique of interpolation according to the temporal autocorrelation of the turbulent fluxes. The gap is filled by the average of effective observations measured simultaneously (the same half an hour) on adjacent days. Generally, the recommended window length is no longer than 2 weeks, because the nonlinear dependence on environmental variables may make large errors and considerable uncertainty over longer periods (Gu et al. 2015). The window length is 5 days in the study.

\section{Results and discussion}

\subsection{The freeze/thaw process}

The division of the freeze/thaw stages was based on soil temperature primarily in previous studies on the freeze/thaw process. Based on the daily minimum/maximum soil temperature, the soil freeze/thaw processes in the whole year were divided into four freeze/thaw stages including the completely frozen stage (daily maximum soil temperature is less than $0{ }^{\circ} \mathrm{C}$ ), the completely thawed stage (daily minimum soil temperature is greater than $0{ }^{\circ} \mathrm{C}$ ), and the freezing and thawing stages (daily maximum soil temperature is greater than $0{ }^{\circ} \mathrm{C}$ and daily minimum soil temperature is less than $0{ }^{\circ} \mathrm{C}$ ) (Guo et al. 2011b). Dividing the freeze/thaw stages of Maduo and Maqu sites with this method, we found that the freezing and thawing stages of the soil layers were generally only $1-2$ days, which was inconsistent with the facts. This inconsistency shows that the freeze/thaw process of soil is complicated, and it is not reliable to divide the freezing and thawing stages only based on soil temperature. Therefore, the freeze/thaw process was divided by the change of soil temperature and soil moisture content in this study, in which the sharp transition of the soil moisture content at each soil layer was detected by a moving $t$ test technique with a step of 15 days. The abrupt change time instants (the significance level $\alpha=0.001$, the $t$ value is $3.5, t \alpha=3.29$, which gives a more strict level of significance) of the soil moisture content around the time when the soil temperature is less than $0{ }^{\circ} \mathrm{C}$ is the thawing process; the abrupt change time instants of the soil moisture content around the time when the soil temperature is more than $0{ }^{\circ} \mathrm{C}$ is the freezing process; the completely frozen stage is between the freezing process and the thawing process; and the completely thawed stage is between the thawing process and the freezing process. The ground diurnal freeze/thaw occurred on every day at the thawing and freezing stages. Based on the method above, four freeze/thaw stages of Maduo site and Maqu site at all depth were defined with a data interval of $30 \mathrm{~min}$ (Table 2).

Table 2 shows the starting dates and periods of the four soil freeze/thaw stages during May 12, 2014, to May 11, 2015. The Maduo site had a longer freezing-thawing period (the freezing stage, the completely frozen stage, and thawing stage) than the Maqu site at every soil depth. On average, the freezing-thawing period persisted approximately 174 days (shallow soil layer, 5-40 cm) and 120 days (deep soil layer, $80-320 \mathrm{~cm}$ ) for the Maduo site (plateau subfrigid semi-arid 
climate zone), only 142 days (shallow soil layer) and 53 days (deep soil layer) for the Maqu site (plateau subfrigid humid climate zone) in the year as shown in Table 2. The starting dates of freezing were delayed as the depth of the soil increased for both Maduo and Maqu sites. In comparison with other sites on the TP, the freezing-thawing process of the BJ (central TP, seasonally frozen ground) and Beiluhe (permafrost) sites persisted approximately 199 days and 208 days, respectively (Ge et al. 2016; Guo et al. 2011b).

As the temperature of the surface soil began to decrease below the freezing point in late October at the Maduo site (Table 2), the soil moisture began to reduce as a result of the soil temperature (Fig. 3a). It took 25 days for Maduo site to reach the completely frozen stage for shallow soil layer. Compared with the Maduo site, the starting date of the freezing process was later and the freezing depths were shallower at the Maqu site (Table 2, Fig. 2b). The soil of Maqu site began to freeze in mid-November; it took 27 days for Maqu site to reach the completely frozen stage for the shallow soil. Compared with other sites of the TP, the surface soil of MS3478 and BJ sites began to freeze in early November; the start dates of the freezing process at the two sites were earlier than at Maqu site but later than at Maduo site. The surface soil of ANNI and D105 sites began to freeze in late and early October, respectively; the start date of the freezing process at the D105 site was earlier than at Maduo site (Chen et al. 2008). After that, the soil was at the completely frozen stage for a long time at both sites. The Maduo site sustained a longer completely frozen period than the Maqu site. For nearly onethird of the year, the shallow soil layer at the Maduo site was in completely frozen stage whereas only for 84 days at the Maqu site. With the increase in solar radiation, the soil temperature rose, and both the surface soil and the soil of the bottom frozen layer began to thaw rapidly at late (early)
March of the following year at the Maduo (Maqu) site. The surface soil of BJ, ANNI, and D105 sites began to thaw in late March, and MS3478 site began in mid-March. The start dates of the thawing process of MS3478 site were earlier than of Maduo site but later than of Maqu site (Chen et al. 2008). The thawing of deep layer soil was faster than of the shallow layer soil (Table 2), because the soil temperature of the deep layer soil was higher than of the shallow layer soil (Fig. 2). The thawing process of the Maqu site was similar to the Maduo site except that the starting dates of the thawing process at Maqu site were earlier than at Maduo site, due to the high soil moisture of Maqu site (Yang et al. 2003). The soil at the depth of $160 \mathrm{~cm}$ of Maqu site was kept in the completely thawed stage throughout the year. Figure 2 indicates that the maximum frozen depth is about $320 \mathrm{~cm}$ at the Maduo site and $90 \mathrm{~cm}$ at the Maqu site. The ground diurnal freeze/thaw occurred on every day of the freezing and thawing stages. As shown in Table 2, it took about 50 days and 58 days of the ground diurnal freeze/thaw process to alternate between the completely frozen/thawed stages in the shallow soil layer of the Maduo and Maqu sites. These durations were shorter than of TGLMS (the Tanggula monitoring station, 83 days) and XDTMS (the Xidatan monitoring station, 132 days) of the permafrost (Yao et al. 2011).

\subsection{Characteristics of soil temperature and soil moisture content}

The daily mean soil temperature and soil moisture content calculated from the data of 30-min interval were used in the following analysis. Although the soil temperature at Maduo site and Maqu site was all at the lowest between January and February (Fig. 2), the variations still existed between the two sites. The temperature of the Maduo site is lower than of the

Table 2 Starting dates and periods of the four soil freeze/thaw stages during May 12, 2014, to May 11, 2015

\begin{tabular}{|c|c|c|c|c|c|c|c|c|}
\hline & \multicolumn{4}{|l|}{ Maduo } & \multicolumn{4}{|l|}{ Maqu } \\
\hline & $\begin{array}{l}\text { The freezing } \\
\text { stage }\end{array}$ & $\begin{array}{l}\text { The } \\
\text { completely } \\
\text { frozen stage }\end{array}$ & $\begin{array}{l}\text { The thawing } \\
\text { stage }\end{array}$ & $\begin{array}{l}\text { The } \\
\text { completely } \\
\text { thawed stage }\end{array}$ & $\begin{array}{l}\text { The freezing } \\
\text { stage }\end{array}$ & $\begin{array}{l}\text { The } \\
\text { completely } \\
\text { frozen stage }\end{array}$ & $\begin{array}{l}\text { The thawing } \\
\text { stage }\end{array}$ & $\begin{array}{l}\text { The } \\
\text { completely } \\
\text { thawed stage }\end{array}$ \\
\hline $2.5 \mathrm{~cm}$ & - & - & - & - & $20141113 / 30$ & $20141213 / 79$ & $20150302 / 41$ & $20150412 / 215$ \\
\hline $5 \mathrm{~cm}$ & $20141023 / 22$ & $20141114 / 130$ & $20150324 / 33$ & $20150426 / 180$ & $20141114 / 27$ & $20141211 / 83$ & $20150304 / 39$ & $20150412 / 216$ \\
\hline $10 \mathrm{~cm}$ & $20141025 / 20$ & $20141114 / 126$ & $20150320 / 20$ & $20150409 / 199$ & $20141121 / 26$ & $20141217 / 90$ & $20150317 / 26$ & $20150412 / 223$ \\
\hline $20 \mathrm{~cm}$ & $20141024 / 32$ & $20141125 / 113$ & $20150318 / 29$ & $20150416 / 191$ & $20141130 / 27$ & $20141227 / 85$ & $20150322 / 23$ & $20150414 / 230$ \\
\hline $40 \mathrm{~cm}$ & $20141103 / 26$ & $20141129 / 125$ & $20150403 / 19$ & $20150422 / 195$ & $20141216 / 25$ & $20150110 / 81$ & $20150401 / 26$ & $20150427 / 233$ \\
\hline $80 \mathrm{~cm}$ & $20141122 / 24$ & $20141216 / 107$ & $20150402 / 21$ & $20150423 / 213$ & $20150113 / 25$ & $20150207 / 60$ & $20150408 / 20$ & $20150428 / 260$ \\
\hline $160 \mathrm{~cm}$ & $20141221 / 20$ & $20150110 / 102$ & $20150422 / 19$ & $20150511 / 224$ & 0 & 0 & 0 & $20140512 / 365$ \\
\hline $320 \mathrm{~cm}$ & $20150209 / 22$ & $20150303 / 14$ & $20150317 / 31$ & $20150417 / 298$ & - & - & - & - \\
\hline $\begin{array}{l}\text { The shallow layer } \\
\text { average }\end{array}$ & 25 & 124 & 25 & 191 & 27 & 84 & 31 & 223 \\
\hline The deep layer average & 22 & 74 & 24 & 245 & 13 & 30 & 10 & 312 \\
\hline
\end{tabular}


Maqu site between January and February; the temperature difference between the two sites was about $4{ }^{\circ} \mathrm{C}$ near the surface layer. The surface temperature, as well as the shallow soil at the two sites, was highest between July and August. There were some differences between the two sites: the soil temperature of the Maqu site was higher than of the Maduo site due to the lower latitude and altitude; the annual mean soil temperature calculated by the daily mean values at the depth of $5 \mathrm{~cm}$ in the Maduo and Maqu site was $2.05^{\circ} \mathrm{C}$ and $5.15^{\circ} \mathrm{C}$, respectively. The Maduo site lies to the northwest of the Maqu site and is higher than the Maqu site. Overall, the soil moisture of the site Maqu was higher than that at site Maduo (Fig. 3). The soil moisture at the two sites decreased with the increase of the soil depth. The soil at the Maduo site was the driest under the depth of $40 \mathrm{~cm}$, and the soil moisture of Maqu site decreased rapidly from the depth of $50 \mathrm{~cm}$ to $80 \mathrm{~cm}$. Unlike the Maduo site, the soil at Maqu site was the driest under the depth of $80 \mathrm{~cm}$ due to the difference of the soil type and the climate type between the sites. Compared with the Maqu site, the soil particle size is coarser at Maduo site; meanwhile, the soil contains plenty of gravel and fine stone. Therefore, the water-holding capability of the soil at Maqu site is higher than at the Maduo site. The climate zone of the Maduo site and the Maqu site is the plateau subfrigid humid and the plateau subfrigid semi-arid, respectively. As the soil moisture is affected by precipitation, the average annual precipitation was $332.5 \mathrm{~mm}$ and $593.4 \mathrm{~mm}$ at Maduo and Maqu, respectively (1981-2010). The daily precipitation of the Maduo and Maqu meteorological stations from May 12, 2014 , to May 11, 2015, shows precipitation mainly occurred between June and September (Fig. 3), which was $72.57 \%$ and $74.95 \%$ of the annual values, respectively. Therefore, the shallow soil water content kept high between June and September (Fig. 3). Due to the lower precipitation of early July at the two sites, the surface and shallow soil water content decreased at the end of July. At the Maduo site and Maqu site, the surface soil started to freeze in October and mid-November respectively and stayed frozen for about 5 months (Table 2). The precipitation decreased (Fig. 3) and the surface soil began to freeze; hence, the shallow soil water content started to decrease at the same time (Fig. 3). In spite of the quite low precipitation of the soil-freezing stage, the soil moisture content was still high at the start of thawing (Fig. 3). This is because the ground temperature decreased as freezing started, and only a little soil liquid water was transferred from the surface soil to the atmosphere through sublimation; most of the water was stored through the frozen soil (Yang et al. 2003).

The diurnal amplitudes of soil temperature of Maduo site were larger than of Maqu site at all freeze/thaw stages (Fig. 4).
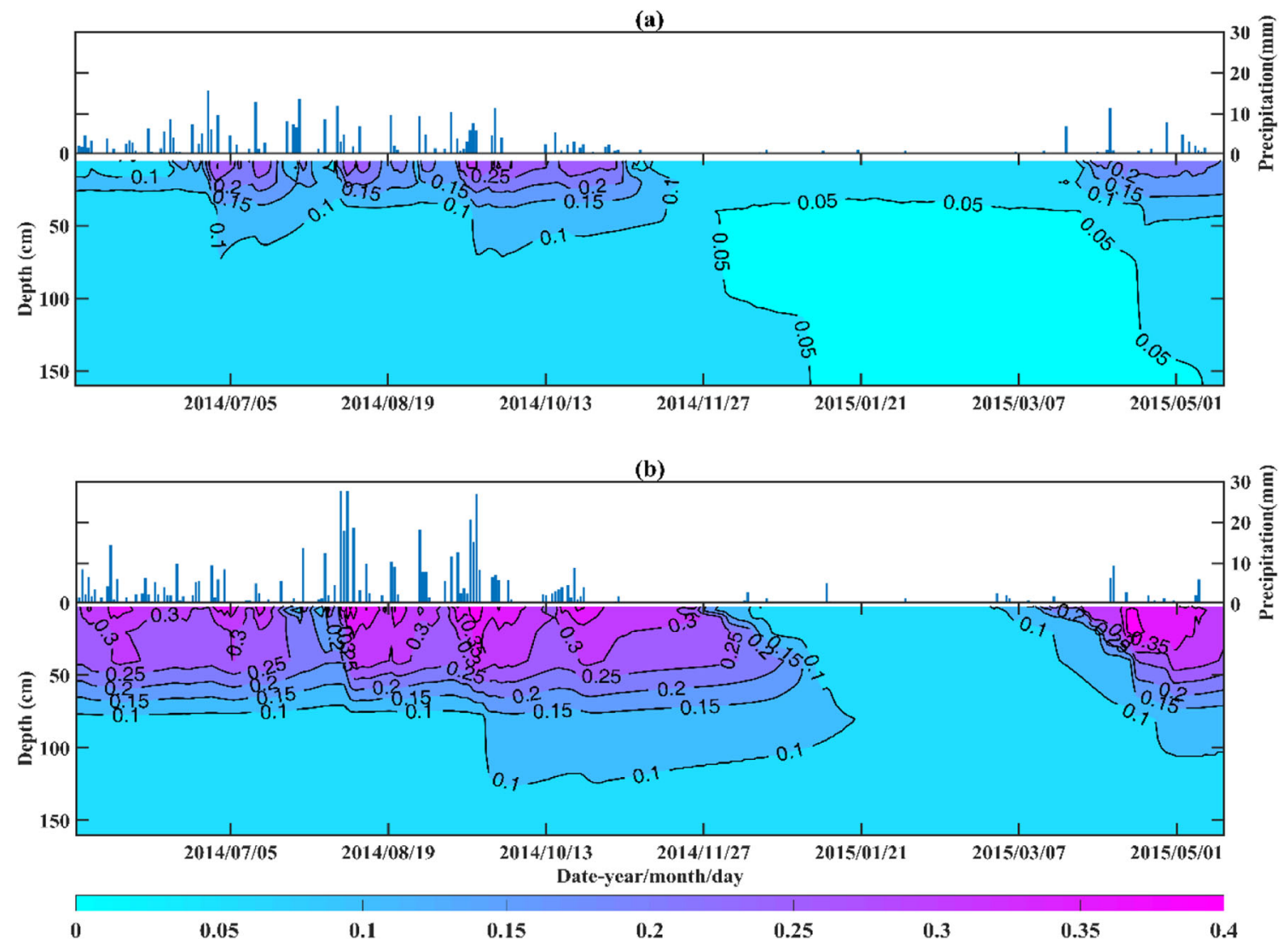

Fig. 3 The daily precipitation and the isotherms of the soil moisture at Maduo (a) and Maqu (b) sites from May 12, 2014, to May 11, 2015. The soil moisture content refers to volumetric content and the intervals are 0.05 


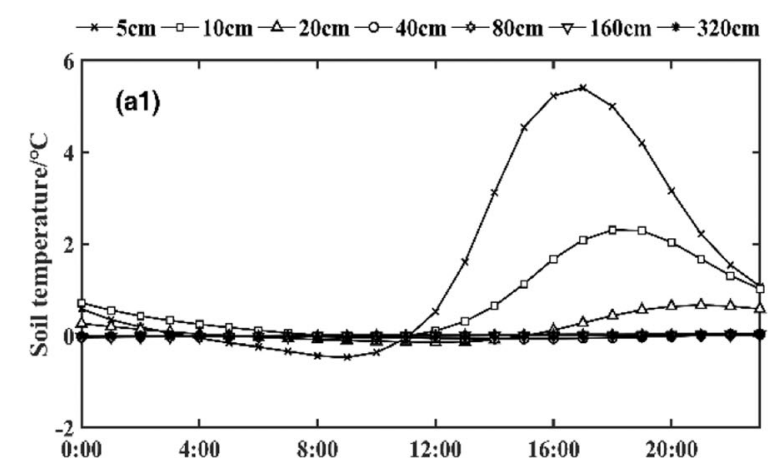

$\neg-2.5 \mathrm{~cm} \rightarrow-5 \mathrm{~cm} \rightarrow-10 \mathrm{~cm} \rightarrow-20 \mathrm{~cm} \rightarrow-0-40 \mathrm{~cm} \rightarrow-80 \mathrm{~cm} \rightarrow-160 \mathrm{~cm}$
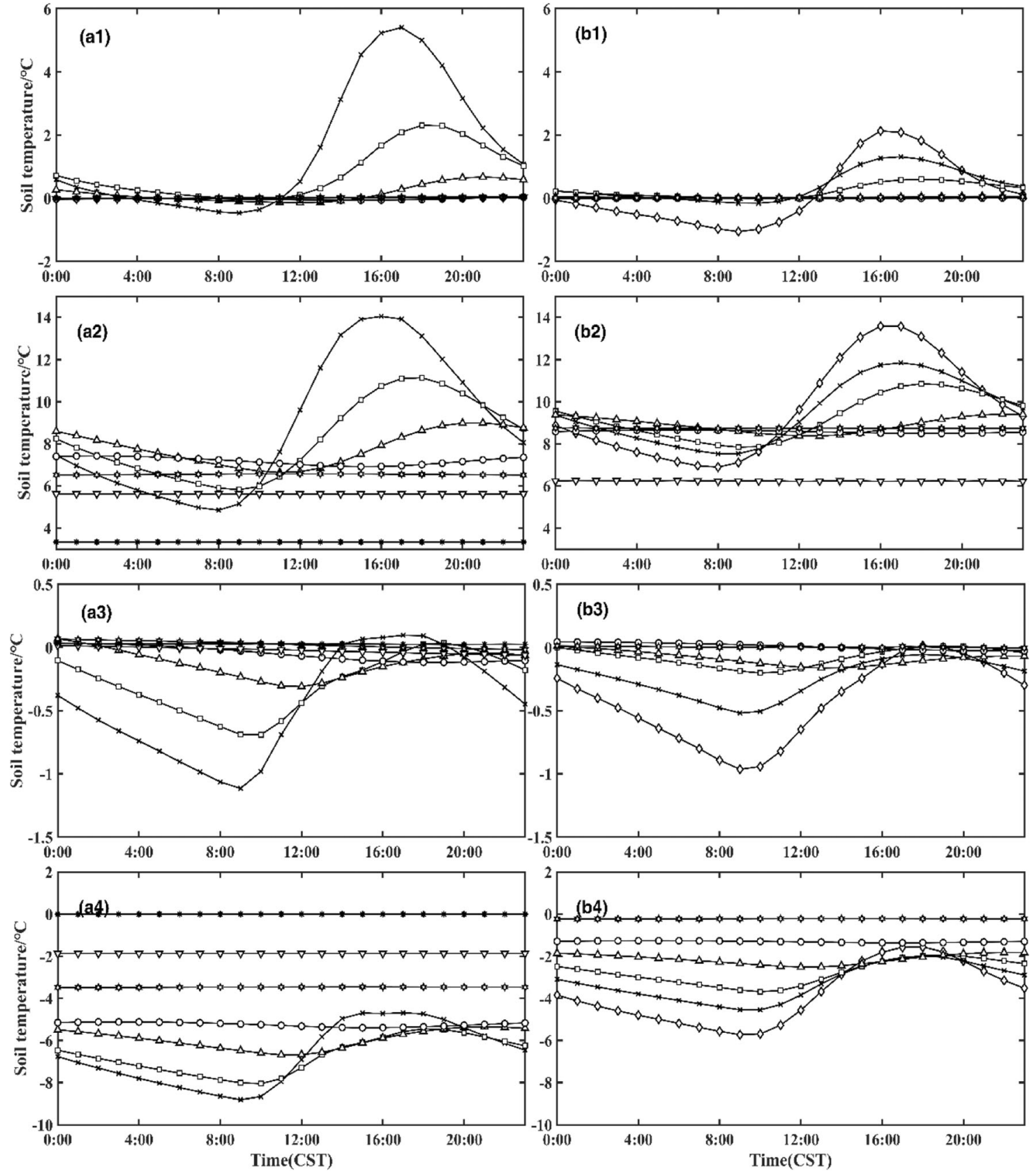

Fig. 4 Diurnal variations of soil temperature of Maduo site (a) and Maqu site (b) at different depths averaged in the thawing (1), completely thawed (2), freezing (3), and completely frozen (4) stages. CST refers to China Standard Time UT+8:00

At the same depth of the soil, diurnal variation patterns of soil temperature were similar between the different stages, and the diurnal amplitudes of the two sites are the largest in the completely thawed stage (9.19 and 4.35), while the least in the freezing stage (1.23 and 0.47). Consistent with the study of Chen et al. (2014), part of the energy is used for phase change in the freezing process, resulting in smaller changes in soil temperature. The soil temperature was slightly higher in the thawing stage than in the completely frozen stage at the depth of $5 \mathrm{~cm}$ of Maduo site, while the opposite was true at the Maqu station. The soil temperature possessed no diurnal variation at all freeze/thaw stages diurnal below the depth of $40 \mathrm{~cm}$ at both Maduo and Maqu sites, and the soil temperature increased with the soil depth in the freezing and the completely frozen stages. The soil temperature decreased with soil depth in the complete thawed stage during daytime because of the large net radiation at the surface. As the soil depth increased, the diurnal cycle of soil temperature variation diminished. 
The diurnal variation of soil moisture decreased with depth (Fig. 5). The soil moisture of the Maqu site was less than that of the Maduo site in the thawing stage, while for the shallow soil layer, Maqu was much wetter than Maduo in the completely thawed stage. The variation of soil moisture the deep soil layer was weak at both sites. The diurnal amplitudes of soil moisture of Maqu site were greater than of Maduo site at all freeze/thaw stages. There was a significant diurnal variation of soil moisture at the two sites during the thawing stage. The soil moisture during the completely thawed stage was sufficient, which resulted in a quite weak diurnal range of the moisture of the shallow soil layer. However, compared with the completely thawed stage, the soil moisture was significant at the shallow soil layer during the completely frozen stage; that is, not all liquid water was converted into ice even during the completely frozen stage, and there still was a diurnal variation of the soil water content due to the surface energy of the soil particles (Chen 2014). The soil always maintained a
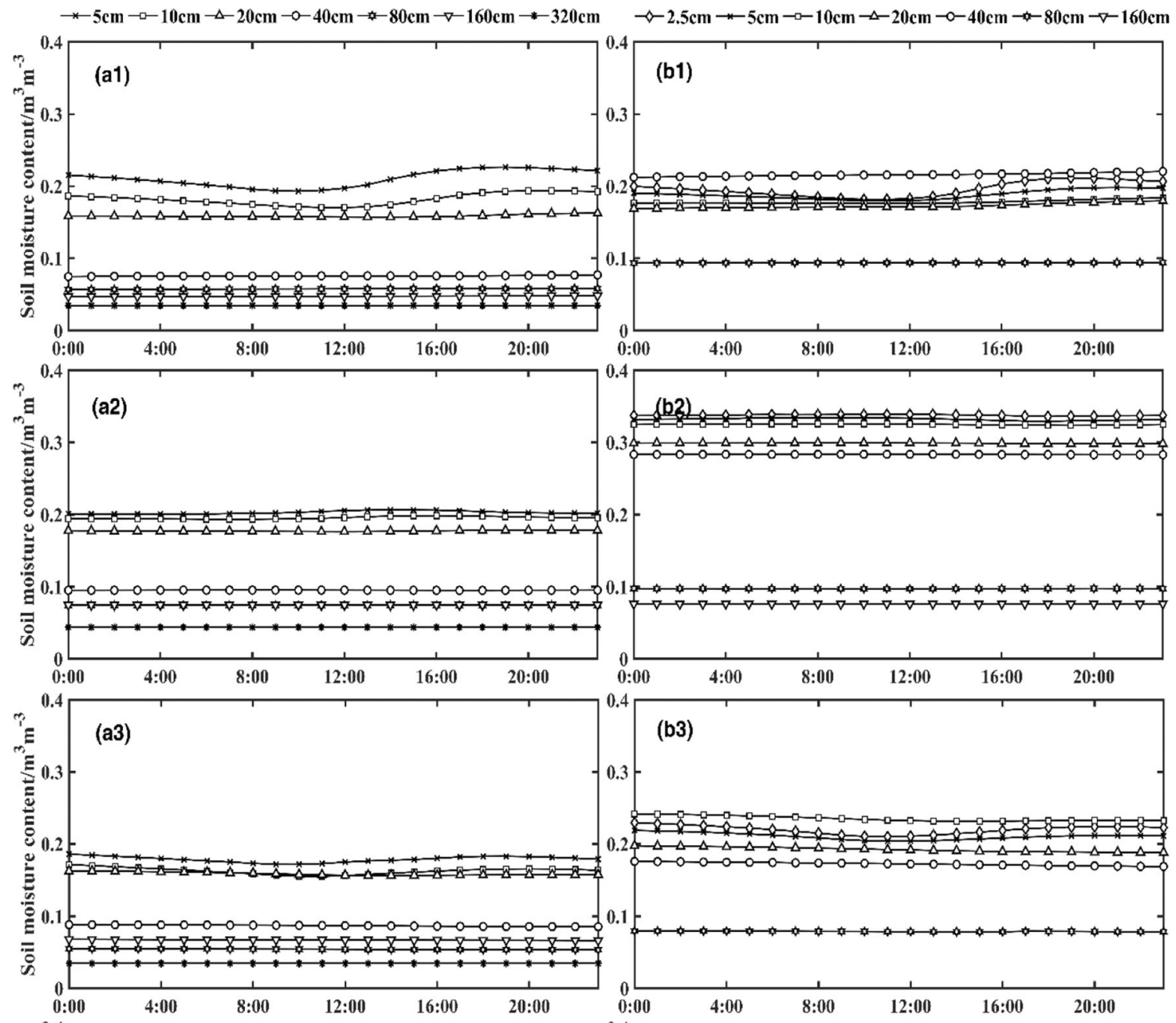

(b3)
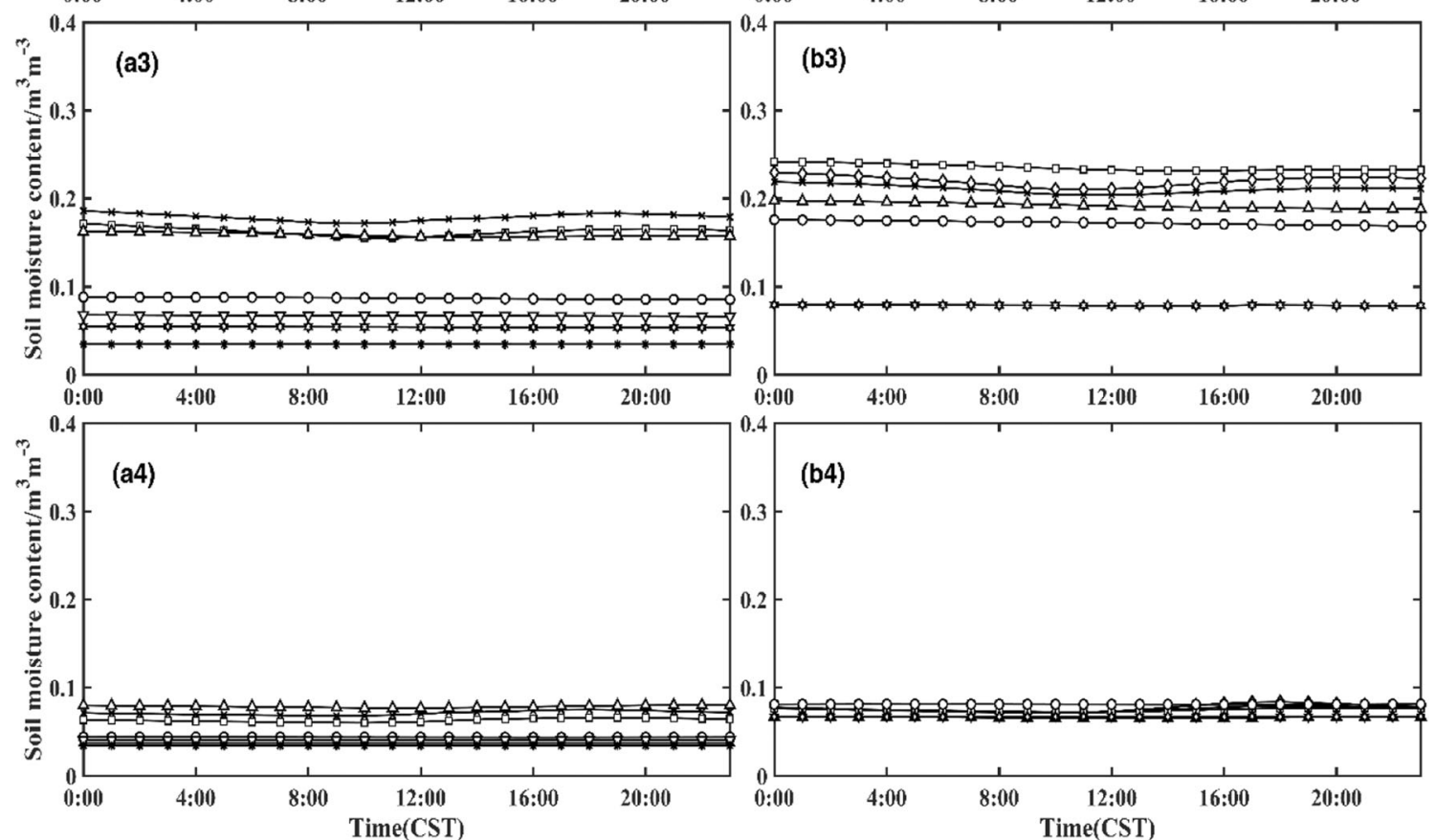

Fig. 5 Diurnal variations of soil moisture content of Maduo site (a) and Maqu site (b) at different depths averaged in the thawing (1), completely thawed (2), freezing (3), and completely frozen (4) stages. CST refers to China Standard Time UT+8:00 
certain amount of liquid water during the completely frozen stage. There was a dynamic equilibrium between soil moisture and soil temperature. The diurnal variation of soil moisture during the completely frozen stage was consistent with the diurnal variation of soil temperature.

\subsection{The variation of flux under different freeze/thaw soil conditions}

Figure 6 shows the annual variations of the daily mean surface energy fluxes at Maduo and Maqu sites. The energy flux variations of the two sites demonstrated certain similarities.

The annual variations of net radiation $(\mathrm{Rn})$ of the Maduo and Maqu sites showed a unimodal change: peaking in summer and plunging in winter. On the one hand, Rn's seasonal trend was affected greatly by the seasonal variation of the subsolar point and the winter snow cover. On the other hand, synoptic weather caused the large day-to-day fluctuation of $\mathrm{Rn}$ as shown in Fig. 6. Rn was hardly influenced by the freeze/thaw process. The variation of the ground surface heat flux $\left(\mathrm{G}_{0}\right)$ was weak compared with $\mathrm{Rn}$. Table 3 shows that mean $\mathrm{G}_{0}$ was negative during the freezing and completely frozen stage, due to the gradual decrease of air temperature and the soil-freezing process. During the two stages, the transport of heat outward from the soil to the atmosphere increased the available energy. The $\mathrm{G}_{0}$ of the freezing stage was greater than of the completely frozen stage at both the Maduo and
Maqu stations. The release of energy from the freezing stage of the soil actually increased the upward intensity of soil heat flux, which is consistent with the simulation results of the previous study (Chen et al. 2014). During the thawing and completely thawed stages, the mean $\mathrm{G}_{0}$ was positive, due to the high air temperature and the thawing of soil absorbing heat. The net effect of the two stages on energy exchange was the absorption of heat by the soil from the atmosphere. The $\mathrm{G}_{0}$ of the thawing stage was greater than of the completely thawed stage at both two sites. The energy absorption from the thawing stage of the soil actually increased the downward soil heat flux. The annual mean values of the $\mathrm{G}_{0}$ at Maduo site and Maqu site were -2.28 and $0.28 \mathrm{~W} / \mathrm{m}^{2}$, respectively. Hence, the overall annual effects of the two sites were different. The heat was transferred from the soil to the atmosphere at Maduo site and absorbed by the soil from the atmosphere at the Maqu site.

During the completely thawed stage, the soil moisture of the shallow soil layer increased (Fig. 3) because the monsoon season increases the precipitation. In addition, the evapotranspiration from the surface soil to the atmosphere increased due to more flourishing vegetation. Therefore, Fig. 6 and Table 3 show that LE was higher than the $\mathrm{H}$ at both sites, the variation of LE was similar to the variation of Rn, and LE predominated in the surface energy distribution. It was shown in a previous study that not only a significant amount of water vapor but also heat energy
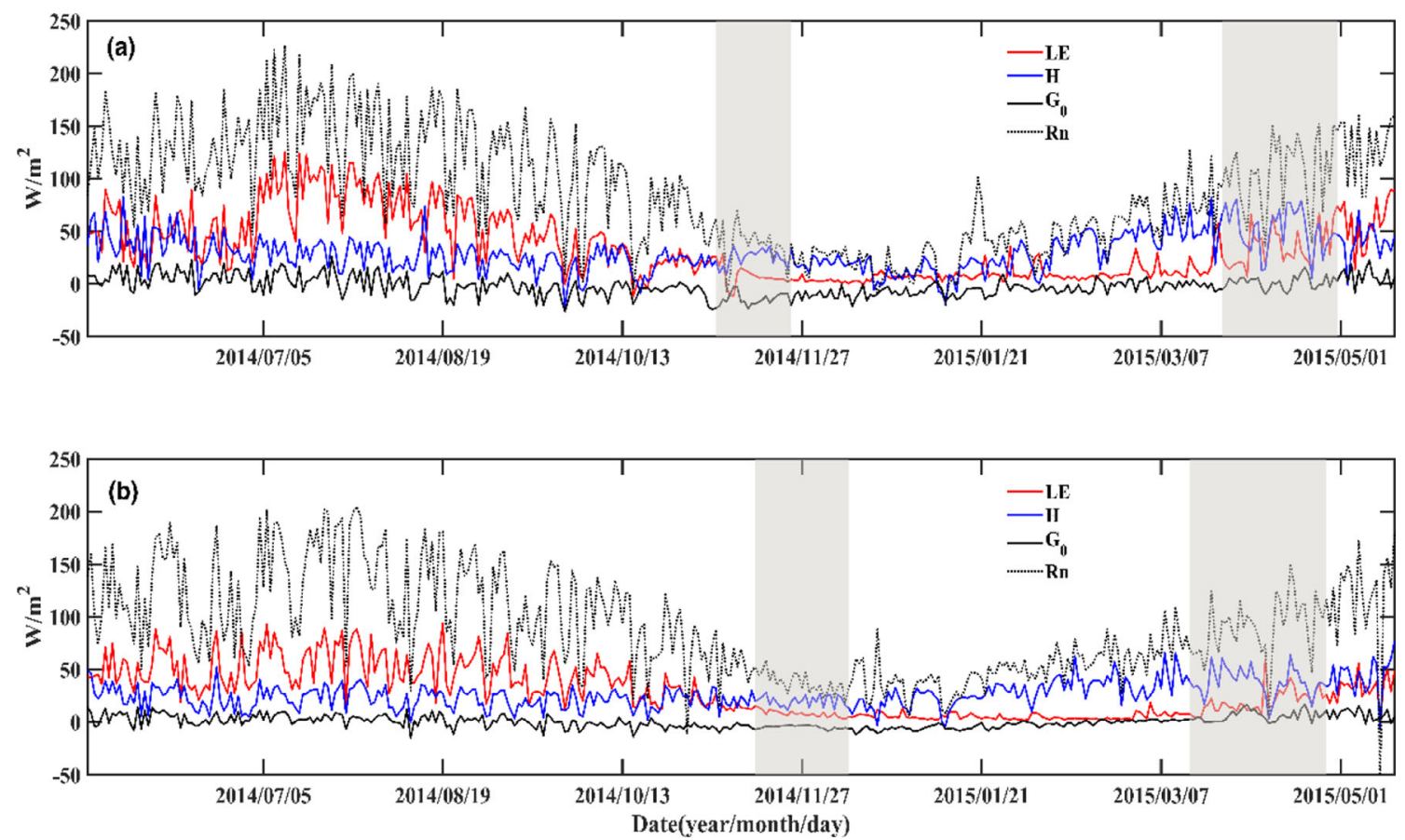

Fig. 6 The daily averages of the surface energy fluxes at Maduo (a) and Maqu (b) sites from May 12, 2014, to May 11, 2015. LE refers to latent heat flux, $\mathrm{H}$ refers to sensible heat flux, $\mathrm{G}_{0}$ refers to the ground surface heat flux, and Rn refers to net radiation. The gray area around November 2014 refers to the freezing stages, and around April refers to the thawing stages 
Table 3 Mean energy components in different freeze/ thaw stages at Maduo and Maqu sites during May 12, 2014, to May 11, 2015

\begin{tabular}{|c|c|c|c|c|c|c|c|c|}
\hline & \multicolumn{4}{|c|}{ Maduo } & \multicolumn{4}{|l|}{ Maqu } \\
\hline & LE & $\mathrm{H}$ & $\mathrm{G}_{0}$ & $\mathrm{Rn}$ & LE & $\mathrm{H}$ & $\mathrm{G}_{0}$ & $\mathrm{Rn}$ \\
\hline The freezing stage & 15.11 & 22.49 & -11.47 & 52.53 & 7.90 & 19.88 & -4.92 & 37.22 \\
\hline The completely frozen stage & 8.75 & 27.16 & -6.29 & 40.75 & 4.66 & 27.03 & -3.53 & 46.61 \\
\hline The thawing stage & 35.21 & 51.48 & 1.21 & 105.70 & 114.17 & 339.22 & 4.04 & 82.03 \\
\hline The completely thawed stage & 55.60 & 28.86 & 1.11 & 121.91 & 443.17 & 25.21 & 1.72 & 113.22 \\
\hline Avg. & 34.63 & 29.92 & -2.28 & 87.35 & 28.70 & 26.72 & 0.28 & 89.12 \\
\hline
\end{tabular}

$L E$, latent heat flux $\left(\mathrm{W} / \mathrm{m}^{2}\right) ; H$, sensible heat flux $\left(\mathrm{W} / \mathrm{m}^{2}\right) ; G_{0}$, ground surface heat flux $\left(\mathrm{W} / \mathrm{m}^{2}\right) ; R n$, net radiation $\left(\mathrm{W} / \mathrm{m}^{2}\right)$ were transferred through evapotranspiration from the soil to the atmosphere; therefore, the reduction of heat energy in the surface soil suppresses the increase of soil temperature, resulting in a decrease of the land-atmosphere temperature difference, thereby reducing the $\mathrm{H}$ (Yang et al. 2003). As showed in Fig. 6a, Rn and LE had a step increase but without a $\mathrm{H}$ decrease at Maduo site. This is because the angle of solar altitude is the largest of the year in late June and early July as we know it, so usually, Rn is the highest value at this time of a year. While as shown in Fig. 6a, there was no increase in Rn before June 27, 2014, which was attributed to the continuous heavy 10-day precipitation (the accumulated precipitation, $47.3 \mathrm{~mm}$ ) from June 18 to June 27 (Fig. 3a). From June 28, more typical sunny days appeared, and Rn increased quickly. Because of the high value of the soil moisture at this time (Fig. 3a), LE has a step increasing by increased $\mathrm{Rn}$. The reason why this change did not exist at Maqu site is that the precipitation in July is less compared with other months, so LE of the Maqu site did not show a step change around July 1, 2014. The shallow soil moisture and the evaporation were weak during the completely frozen stage, resulting in a low LE. As the $\mathrm{H}$ predominated in the surface energy distribution, the variation of $\mathrm{H}$ is similar to the variation of Rn. During the freezing stage, the soil liquid water began to reduce while freezing, which caused the weak increase of $\mathrm{H}$ and decrease of LE. However, the LE started to decrease before the soil-freezing, which indicates the effect of soil-freezing for the variation of LE is weak. The $\mathrm{H}$ started to increase with the Rn before the soil thawed. The Rn still increased with the change of season during the thawing stage, causing the weak increase of the $\mathrm{H}$ and the enhancement of LE. The contribution of the thawed water to latent heat flux was durative, and the contribution continued with the durative thawing process (Yao et al. 2011). In addition, in soils, the thawing edge of the active layer prevented downward penetration during the thawing stage. This may result in more water accumulated on the surface layer soils, thus allowing more available water to evaporate. Overall, the variations of fluxes were affected by both the monsoon and the freeze/thaw process of the soil layer in the seasonally frozen region.

\subsection{Diurnal variation of flux under different freeze/thaw soil conditions}

The soil temperature at the depth of $5 \mathrm{~cm}$ was above $0{ }^{\circ} \mathrm{C}$, and the diurnal variation was significant at both sites during the completely thawed stage (Fig. 4a2, b2). Soil moisture was sufficient for both daytime and nighttime because of the abundant rainfall during the completely thawed stage, which resulted in a quite weak diurnal range (Fig. 5a2, b2). During the completely thawed stage, the diurnal variations of the LE were greater than of $\mathrm{H}$ at both sites as shown in Fig. 7a2, b2, because LE produced by evaporation was larger during the day and smaller during nighttime due to the absence of solar radiation heating (Fig. 7a2, b2). Therefore, the variation of LE is consistent with the variation of $\mathrm{Rn}$, and although the solar radiation heating was high during daytime at the completely thawed stage, the $\mathrm{H}$ was still small, which results from the heat of evaporation absorbed from the soil surface water. In addition, the $\mathrm{H}$ was also small during nighttime, resulting in a relatively low range of daily variation. The diurnal variation of $\mathrm{G}_{0}$ was significant in the completely thawed stage.

During the completely frozen stage, the soil temperature at the depth of $5 \mathrm{~cm}$ is $<0{ }^{\circ} \mathrm{C}$. Because the soil maintained a certain amount of unfrozen liquid water in the stage, the LE still has a diurnal variation, although the range is weak because of the quite low diurnal range of soil moisture (Fig. 5a4, b4). Solar radiation was mainly distributed to $\mathrm{H}$; hence, the diurnal variation of the $\mathrm{H}$ was greater than of the LE. The diurnal change of Rn during the completely frozen stage was significantly smaller than of other stages, which may be due to the thermal insulation effect and the large albedo of the snow cover during the completely frozen stage.

During the freezing and thawing stage, the soil moisture was pronouncedly greater in the completely frozen stage at the depth of $5 \mathrm{~cm}$ (Fig. 5a2, b2). However, due to the influence of the daily freeze/thaw cycle on the shallow soil layer, the LE was still small in the daytime. The soil moisture during 

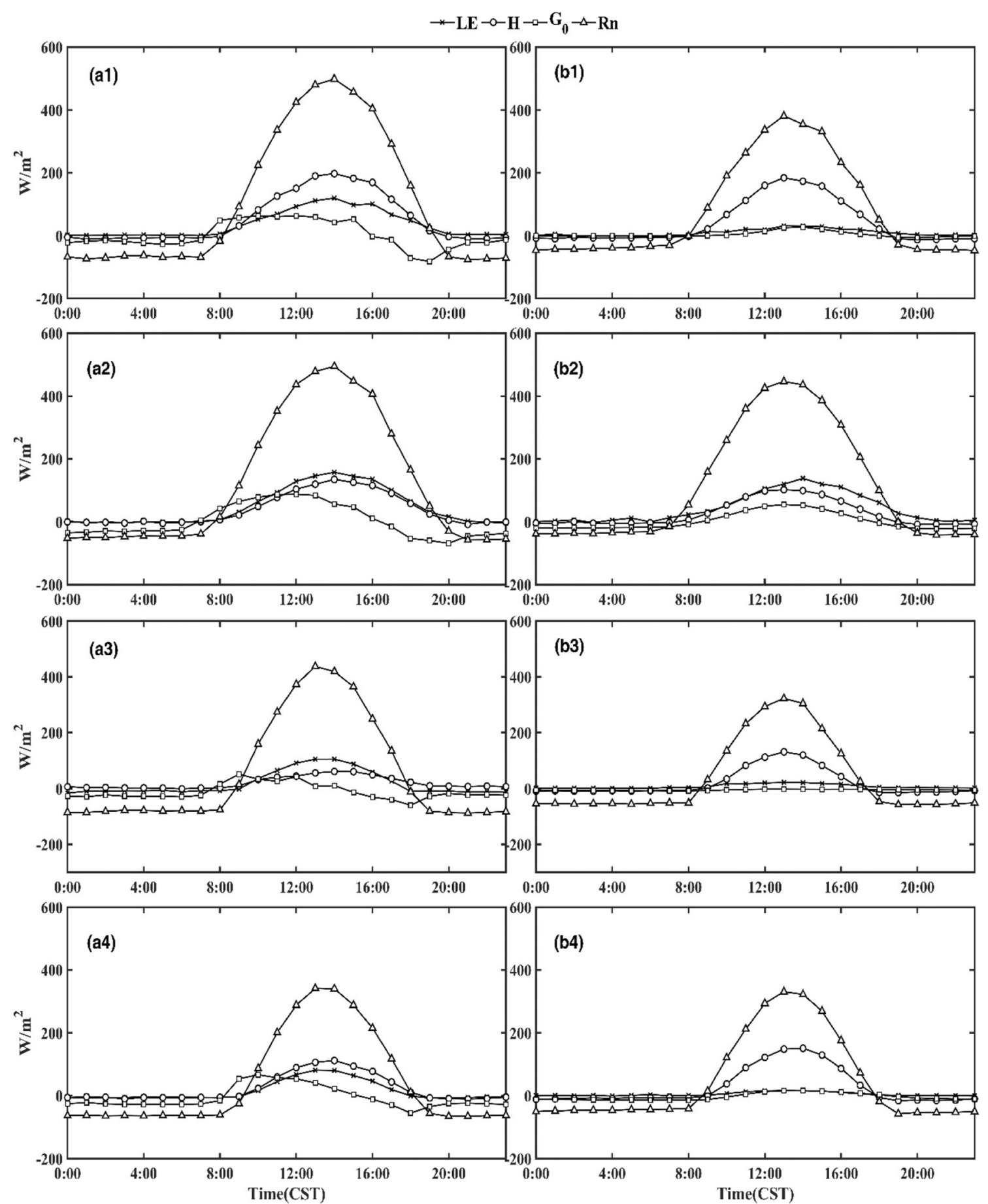

Fig. 7 Diurnal variations of the surface energy fluxes of Maduo site (a) and Maqu site (b) in the thawing (1), completely thawed (2), freezing (3), and completely frozen (4) stages. LE refers to latent heat flux, $\mathrm{H}$ refers to

sensible heat flux, $\mathrm{G}_{0}$ refers to the ground surface heat flux, Rn refers to net radiation, and CST refers to China Standard Time UT+8:00

daytime decreased first and then increased, which was opposite to the diurnal variation of net radiation. That is, the surface soil moisture was weak when the net radiation was large, and the negative change inhibits the increase of LE during the daytime. A previous simulation study (Guo et al. 2011b) indicates that the LE is significant during the freezing stage, and the variance may be due to the inaccuracy of soil liquid water simulation. The diurnal variation of $\mathrm{H}$ during the thawing stage was larger than that occurred in the completely thawed stage. This may be due to the primary allocation of solar radiation to the latent heat of evaporation because of high precipitation during the completely thawed stage (Guo et al. 2011a). $G_{0}$ was the smallest during the freezing stage, due to the weak diurnal variation of soil temperature and small soil 
moisture in the stage, which resulted in the smaller values of $\Delta \mathrm{g}$ in the stage compared with those in others. The freeze/ thaw process had a significant effect on the diurnal change of $\mathrm{G}_{0}$ during the freezing stage.

\subsection{Energy closure status}

The status of energy closure is an important criterion for evaluating the quality of the flux data (Aubinet et al. 2012; Foken 2008; Foken and Napo 2008; Leuning et al. 2005). The energy closure ratio $(\mathrm{CR})$ is defined as follows:

$$
\mathrm{CR}=\frac{H+L E}{R n-G_{0}}
$$

CR being closer to 1.00 shows the energy closure status is better. In the past decades, many studies have been reported about the energy balance closure: the turbulent fluxes (the sum of the LE and $\mathrm{H}$ ) are usually smaller than the surface effective energy, which is the difference between the Rn and the $\mathrm{G}_{0}$ (Barr et al. 2012; Foken et al. 2006; Franssen et al. 2010; Gu et al. 2015; Heilman et al. 2009; Mauder et al. 2013; Wilson et al. 2002). Many scientists have discussed the problem about why the energy balance is not close (Culf et al. 2004; Foken et al. 2006; Gu et al. 2015; Wang et al. 2009): (1) measurement errors, particularly the $\mathrm{H}$ and LE, might be underestimated by the eddy covariance method; (2) the different equilibrium layers and the different measurement method scales, discussed in energy storage in the soil and the canopy; (3) the differences of the land surface; and (4) a loss in the low-frequency band.

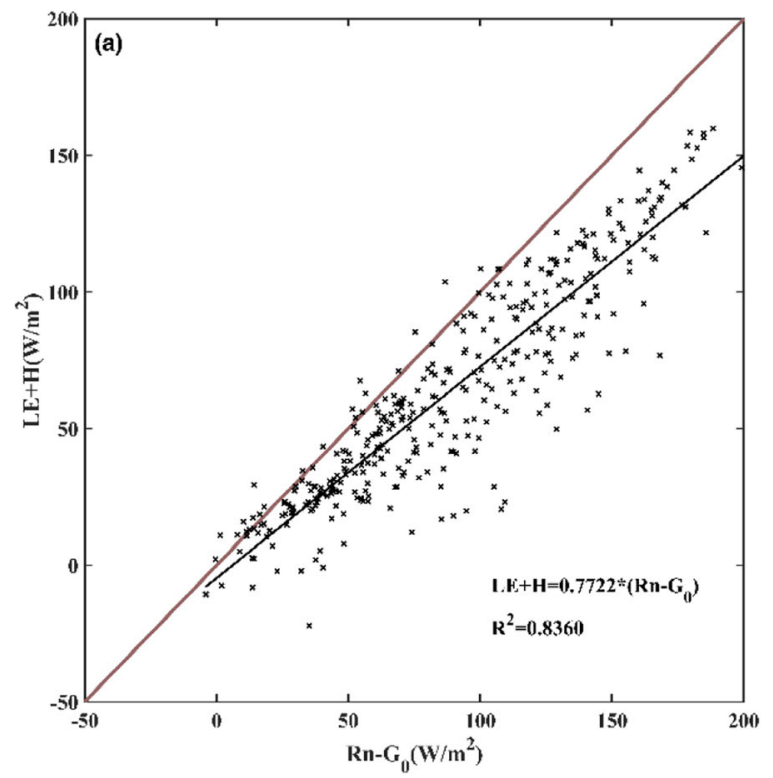

Studies about the energy of the TP show that the energy closure status during daytime is better than that during nighttime, and it is also better in a sunny day and not in a cloudy, rainy, or snowy day ( $\mathrm{Li}$ et al. 2008). Therefore, some researches calculate the energy closure status only on the typical sunny days (Ao et al. 2008). In order to analyze the annual variation of the energy closure status and the effect of the freeze/thaw process on the energy closure status, all times were calculated in this study, resulting in a low energy closure, compared with the studies that only consider sunny days.

Figure 8 shows the energy closure status by using the daily average flux data at Maduo site (a) and Maqu site (b) from May 12, 2004, to May 11, 2005. The daily average flux data was used mainly because studies show that the energy closure status is also related to the temporal scales (Gu et al. 2015; Yao et al. 2011). The energy closure status of the two sites was 0.77 and 0.58 , respectively. The energy closure status of the Maduo site was better than that of the Maqu site. The reason for the lower energy closure status of the Maqu site may be the high grass, which resulted in the neglect of the energy transferred from the canopy in the calculation of the energy closure status. The energy closure status with daily average flux data at BJ site and Tanggula site was 0.87 and 0.99 , respectively (Gu et al. 2015), greater than those of Maduo and Maqu sites, which is due to the difference in vegetation types.

The energy closure status of the Maduo site during the completely thawed stage was 0.92 (Fig. 9a2), which was higher than those in other stages and the annual energy closure status (0.77) (Fig. 8a). Because the grass of the underlying surface was higher in summer at the Maqu site, the influence of canopy energy transmission decreased the energy closure status (0.57) at Maqu in the completely thawed stage (Fig. 9b2). Instead, the energy closure status of Maqu site is the highest (0.78) during the thawing stage (Fig. 9b1). The

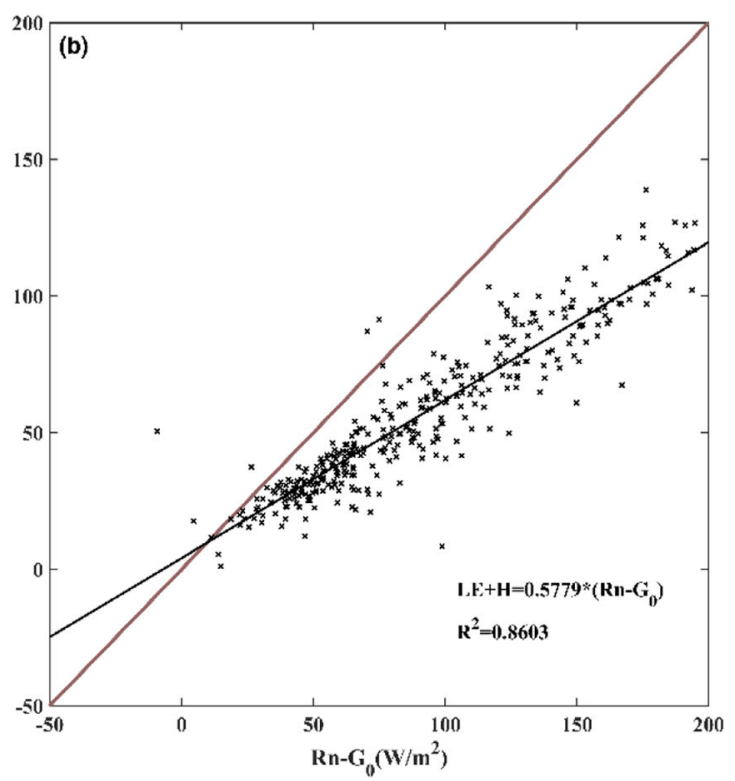

Fig. 8 Energy closure ratio using daily average flux data at Maduo site (a) and Maqu site (b) during May 12, 2014, to May 11, 2015 

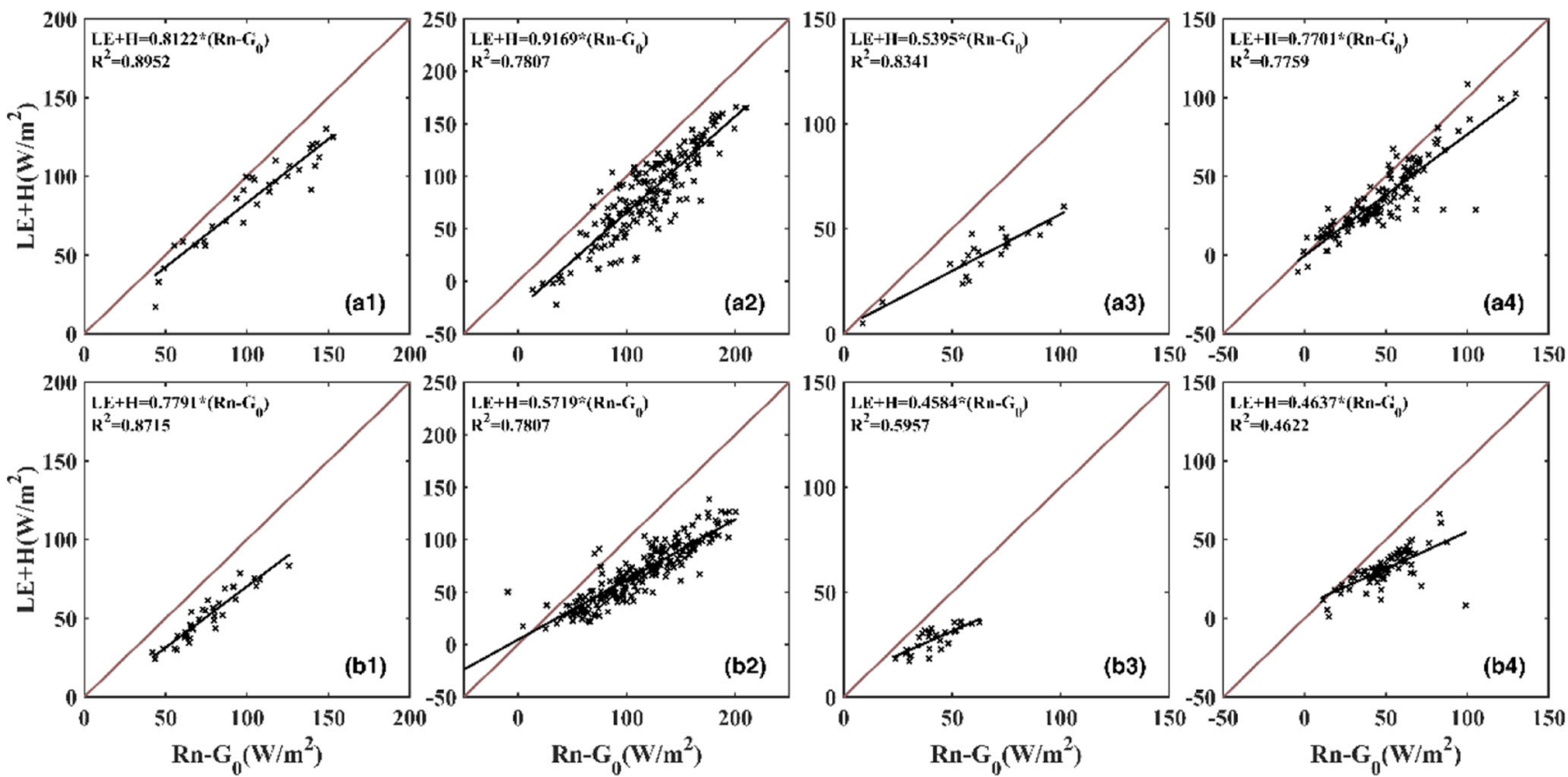

Fig. 9 Energy closure ratio of Maduo site (a) and Maqu site (b) averaged in the thawing (1), completely thawed (2), freezing (3), and completely frozen (4) stages

energy closure status of both sites was the lowest during the freezing stage, 0.54 (Fig. 9a3) at Maduo and 0.46 (Fig. 9b3) at Maqu. Generally, during the freezing stage, CR $>1$ occurs as a result of the overestimation of $\mathrm{G}_{0}$ because of the heat released by the freezing process from the frozen soil water during the freezing stage (Guo et al. 2011a). Our results of CR were different from the previous study, which may be related to snow cover (Guo et al. 2011a). Due to the wind and direct radiation, the evaporation and sublimation rates of the snow were high. Therefore, the energy budget did not reach closure, and the $\mathrm{CR}$ was poor (Gu et al. 2015). In addition, the thermal conductivity of ice is not considered during the freezing and completely frozen stage during the calculation of $\mathrm{G}_{0}$, which may result in errors of $\mathrm{G}_{0}$. Overall, the freeze/thaw process had a certain effect on the energy closure status, but less than in the impact of the high albedo caused by snow cover on the energy closure status.

\section{Conclusions}

This paper analyzes the freeze/thaw process and the surface energy budget of the seasonally frozen ground in the source region of the Yellow River, using observation data from the Maduo and Maqu sites from May 12, 2014, to May 11, 2015. The annual and daily changes of soil temperature, soil moisture, and surface energy flux with different freeze/thaw stages were obtained. The start and end time of each freeze/thaw stage were determined by a new method utilizing the diurnal cycle of soil temperature and water content. The comparison of freezing-thawing periods, soil temperature, soil moisture, and surface energy flux was conducted between the two sites.
The Maduo site had the longer freezing-thawing periods (the completely frozen stage, the freezing and thawing stages) than the Maqu site at every depth of soil. Compared with the Maduo site, the starting date of the freezing process was later and the freezing depth was shallower at the Maqu site. It took 25 and 27 days for Maduo and Maqu sites respectively to reach the completely frozen stage for shallow soil layer. The Maduo site (124 days) had the longer completely frozen periods than the Maqu site (84 days). The starting dates of the thawing process at Maqu site were earlier than at Maduo site, due to the high soil moisture of Maqu site. The maximum frozen depth was about $320 \mathrm{~cm}$ at Maduo site and $90 \mathrm{~cm}$ at the Maqu site.

The soil temperature of the Maqu site was higher than of the Maduo site due to the lower latitude and altitude. The soil moisture at the two sites decreased with the increase of the soil depth. The soil at the Maduo site was the driest under the depth of $40 \mathrm{~cm}$. The soil moisture of Maqu site decreased rapidly from the depth of $50 \mathrm{~cm}$ to $80 \mathrm{~cm}$, with the driest soil lying below the depth of $80 \mathrm{~cm}$. These differences are due to the different soil types and the climate types between the sites.

The diurnal amplitudes of soil temperature of Maduo site were larger than of Maqu site at all freeze/thaw stages, and the amplitudes are the largest in the completely thawed stage (9.19 and 4.35), while the minimum amplitude occurred in the freezing stage (1.23 and 0.47$)$ due to the phase change. The diurnal amplitudes of soil moisture of Maqu site were greater than of Maduo site at all freeze/thaw stages. Compared with the completely thawed stage, the soil moisture is significantly lower at the shallow soil layer during the completely frozen stage. 
The annual variations of net radiation $(\mathrm{Rn})$ of the Maduo and Maqu sites showed a similar pattern: a unimodal change related to solar insolation with synoptic scale fluctuations. Rn's seasonal change was hardly influenced by the freeze/thaw process. The mean $\mathrm{G}_{0}$ was negative during the freezing and completely frozen stages, and positive during the thawing and completely thawed stages. The annual mean values of the $\mathrm{G}_{0}$ at Maduo site and Maqu site were -2.28 and $0.28 \mathrm{~W} / \mathrm{m}^{2}$, respectively. Hence, the overall annual effects of the two sites were different. The heat was transferred from the soil to the atmosphere at Maduo site and absorbed by the soil from the atmosphere at the Maqu site. During the completely thawed stage, the soil moisture of the shallow soil layer increased; the LE predominated in the surface energy distribution. The shallow soil moisture and the evaporation were weak during the completely frozen stage, resulting in the low LE. The $\mathrm{H}$ predominated in the surface energy distribution. Overall, the variations of fluxes were affected by both the monsoon and the freeze/thaw process of the soil layer in the seasonally frozen region.

During the completely thawed stage, the diurnal range of the LE was greater than $\mathrm{H}$ at both sites. During the complete frozen stage, the range of LE was weak because of the small diurnal range of unfrozen soil water content. The diurnal variation of $\mathrm{Rn}$ in the completely frozen stage was distinctly weaker than those in other stages, which may be caused by the thermal insulation and the large albedo of the snow cover in the completely frozen stage. $\mathrm{G}_{0}$ was the greatest during the completely thawed stage and the smallest in the freezing stage, which was due to the weak diurnal variation of soil temperature and small soil moisture in the stage. The freeze/thaw process had a significant effect on the diurnal change of $\mathrm{G}_{0}$ during the freezing stage.

The annual energy closure status was 0.77 at the Maduo site and 0.58 at the Maqu site. The energy closure status of the Maduo site is better than that of the Maqu site. The energy closure status of the Maduo site during the completely thawed stage was 0.92 , which is higher than those in other stages and the annual energy closure status (0.77). The energy closure status of Maqu site was the highest $(0.78)$ during the thawing stage. The energy closure status during the freezing stage was 0.54 at Maduo site and 0.46 at Maqu site; both are the lowest among the four stages, due to the snow cover's impact on surface energy exchange. Overall, the freeze/thaw process had a certain effect on the energy closure status, but less than the impact of the high albedo caused by snow cover on the energy closure status.

Funding information This work was supported by the National Natural Science Foundation of China (Nos. 91537104 and 41775016).

Open Access This article is distributed under the terms of the Creative Commons Attribution 4.0 International License (http:// creativecommons.org/licenses/by/4.0/), which permits unrestricted use, distribution, and reproduction in any medium, provided you give appropriate credit to the original author(s) and the source, provide a link to the Creative Commons license, and indicate if changes were made.

\section{References}

Ao Y, Lyu S, Li S, Zhang Y, Chen SQ, Shang LY (2008) The energy budget and microclimate over the upper Yellow River in summer fine days. J Glaciol Geocryol 30(3):426-432

Aubinet M, Vesala T, Papale D (2012) Eddy covariance: a practical guide to measurement and data analysis. Springer Science Atmospheric Sciences

Barr AG, van der Kamp G, Black TA, McCaughey JH, Nesic Z (2012) Energy balance closure at the BERMS flux towers in relation to the water balance of the White Gull Creek watershed 1999-2009. Agric For Meteorol 153:3-13. https://doi.org/10.1016/j.agrformet.2011.05.017

Chen BL (2014) A study of land surface energy and water in soil freezing and thawing process and impact on regional climate of the QinghaiTibet Plateau. Dissertation, Cold and arid regions environmental and engineering research

Chen XL, Ma YM, Li MS, Ma WQ, Wang H (2008) Analyses on near surface layer atmospheric characteristics and soil features in northern Tibetan Plateau. Plateau Meteorol 27(5):941-948. https://doi. org/10.3724/SP.J.1047.2008.00014

Chen BL, Luo SQ, Lu SH, Zhang Y, Ma D (2014) Effects of the soil freeze-thaw process on the regional climate of the Qinghai-Tibet Plateau. Clim Res 59(3):243-257. https://doi.org/10.3354/cr01217

Culf AD, Foken T, Gash JH (2004) The energy balance closure problem. In: Vegetation, water, humans and the climate. Springer, Berlin, pp 159-166

Duguay CR, Zhang T, Leverington DW, Romanovsky VE (2013) Remote sensing of permafrost and seasonally frozen ground. In: Remote Sensing in Northern Hydrology: Measuring Environmental Change. American Geophysical Union, pp 91-118

Falge E, Baldocchi D, Olson R, Anthoni P, Aubinet M, Bernhofer C, Burba G, Ceulemans R, Clement R, Dolman H, Granier A, Gross P, Grünwald T, Hollinger D, Jensen NO, Katul G, Keronen P, Kowalski A, Lai CT, Law BE, Meyers T, Moncrieff J, Moors E, Munger JW, Pilegaard K, Rannik Ü, Rebmann C, Suyker A, Tenhunen J, Tu K, Verma S, Vesala T, Wilson K, Wofsy S (2001) Gap filling strategies for defensible annual sums of net ecosystem exchange. Agric For Meteorol 107(1):43-69. https://doi.org/10. 1016/S0168-1923(00)00225-2

Foken T (2008) The energy balance closure problem: An overview. Ecol Appl 18(6):1351-1367. https://doi.org/10.1890/06-0922.1

Foken T, Napo CJ (2008) Micrometeorology, vol 2. Springer, Berlin

Foken T, Wimmer F, Mauder M, Thomas C, Liebethal C (2006) Some aspects of the energy balance closure problem. Atmos Chem Phys 6: 4395-4402. https://doi.org/10.5194/acp-6-4395-2006

Franssen HJH, Stockli R, Lehner I, Rotenberg E, Seneviratne SI (2010) Energy balance closure of eddy-covariance data: a multisite analysis for European FLUXNET stations. Agric For Meteorol 150(12): 1553-1567. https://doi.org/10.1016/j.agrformet.2010.08.005

Ge J, Yu Y, Li Z, Jie J, Liu C, Zai B (2016) Impacts of freeze/thaw processes on land surface energy fluxes in the permafrost region of Qinghai-Xizang Plateau. Plateau Meteorol 35(3):608-620

Gu LL, Yao JM, Hu ZY, Zhao L (2015) Comparison of the surface energy budget between regions of seasonally frozen ground and permafrost on the Tibetan plateau. Atmos Res 153:553-564. https://doi.org/10. 1016/j.atmosres.2014.10.012

Guo DL, Wang HJ (2013) Simulation of permafrost and seasonally frozen ground conditions on the Tibetan Plateau, 1981-2010. J Geophys Res-Atmos 118(11):5216-5230. https://doi.org/10.1002/jgrd.50457

Guo DL, Wang HJ (2014) Simulated change in the near-surface soil freeze/ thaw cycle on the Tibetan Plateau from 1981 to 2010. Chin Sci Bull 59(20):2439-2448. https://doi.org/10.1007/s11434-014-0347-x

Guo DL, Yang MX, Wang HJ (2011a) Characteristics of land surface heat and water exchange under different soil freeze/thaw conditions over the central Tibetan Plateau. Hydrol Process 25(16):2531-2541. https://doi.org/10.1002/hyp.8025 
Guo DL, Yang MX, Wang HJ (2011b) Sensible and latent heat flux response to diurnal variation in soil surface temperature and moisture under different freeze/thaw soil conditions in the seasonal frozen soil region of the central Tibetan Plateau. Environ Earth Sci 63(1):97-107. https://doi.org/10.1007/s12665-010-0672-6

Heilman JL, McInnes KJ, Kjelgaard JF, Owens MK, Schwinning S (2009) Energy balance and water use in a subtropical karst woodland on the Edwards Plateau, Texas. J Hydrol 373(3-4):426-435. https://doi.org/10.1016/j.jhydrol.2009.05.007

Heusinkveld BG, Jacobs AFG, Holtslag AAM, Berkowicz SM (2004) Surface energy balance closure in an arid region: role of soil heat flux. Agric For Meteorol 122(1-2):21-37. https://doi.org/10.1016/j. agrformet.2003.09.005

Hu YR, Maskey S, Uhlenbrook S, Zhao HL (2011) Streamflow trends and climate linkages in the source region of the Yellow River, China. Hydrol Process 25(22):3399-3411. https://doi.org/10.1002/hyp.8069

$\mathrm{Hu}$ YR, Maskey S, Uhlenbrook S (2012) Trends in temperature and rainfall extremes in the Yellow River source region, China. Clim Chang 110(12):403-429. https://doi.org/10.1007/s10584-011-0056-2

Jin H, He R, Cheng G, Wu Q, Wang S, Lü L, Chang X (2009) Changes in frozen ground in the source area of the Yellow River on the Qinghai-Tibet Plateau, China, and their eco-environmental impacts. Environ Res Lett 4(4):045206

Jin H, Wang S, Lv L, He R, Chang X, Luo D (2010) Features and degradation of frozen ground in the sources area of the Yellow River, China. J Glaciol Geocryol 32(1):10-17

Lan YC, Zhao GH, Zhang YN, Wen J, Liu JQ, Hu XL (2010) Response of runoff in the source region of the Yellow River to climate warming. Quat Int 226(1-2):60-65. https://doi.org/10.1016/j. quaint.2010.03.006

Leuning R, Cleugh HA, Zegelin SJ, Hughes D (2005) Carbon and water fluxes over a temperate Eucalyptus forest and a tropical wet/dry savanna in Australia: measurements and comparison with MODIS remote sensing estimates. Agric For Meteorol 129(3):151-173

Li S, Nan Z, Zhao L (2002) Impact of soil freezing and thawing process on thermal exchange between atmosphere and ground surface. J Glaciol Geocryol 24(5):506-511

Li Q, Zhang XZ, Shi PL, He Y, Xu L, Sun W (2008) Study on the energy balance closure of alpine meadow on Tibetan Plateau. J Nat Resour 23(3):391-399

Li R, Zhao L, Ding YJ, Wu TH, Xiao Y, du EJ, Liu GY, Qiao YP (2012) Temporal and spatial variations of the active layer along the Qinghai-Tibet highway in a permafrost region. Chin Sci Bull 57(35):4609-4616. https://doi.org/10.1007/s11434-012-5323-8

Li K, Li X, Wang C, Qiao Y (2013) Research on the environmental effect caused by climate change in the source region of the Yellow River. J Glaciol Geocryol 35(5):1183-1192

Li ZG, Lyu SH, Ao YH, Wen LJ, Zhao L, Wang SY (2015) Long-term energy flux and radiation balance observations over Lake Ngoring, Tibetan Plateau. Atmos Res 155:13-25. https://doi.org/10.1016/j. atmosres.2014.11.019

Liebethal C, Huwe B, Foken T (2005) Sensitivity analysis for two ground heat flux calculation approaches. Agric For Meteorol 132(3-4):253262. https://doi.org/10.1016/j.agrformet.2005.08.001

Luo SQ, Fang XW, Lyu SH, Ma D, Chang Y, Song MH, Chen H (2016) Frozen ground temperature trends associated with climate change in the Tibetan Plateau three river source region from 1980 to 2014. Clim Res 67(3):241-255. https://doi.org/10.3354/cr01371

Luo SQ, Fang XW, Lyu SH, Jiang Q, Wang JY (2017) Interdecadal changes in the freeze depth and period of frozen soil on the three rivers source region in China from 1960 to 2014. Adv Meteorol: 5931467. https://doi.org/10.1155/2017/5931467

Ma Y, Fan S, Ishikawa H, Tsukamoto O, Yao T, Koike T, Zuo H, Hu Z, Su Z (2005) Diurnal and inter-monthly variation of land surface heat fluxes over the central Tibetan Plateau area. Theor Appl Climatol 80(2-4):259-273. https://doi.org/10.1007/s00704-004-0104-1
Mauder M, Cuntz M, Drüe C, Graf A, Rebmann C, Schmid HP, Schmidt M, Steinbrecher R (2013) A strategy for quality and uncertainty assessment of long-term eddy-covariance measurements. Agric For Meteorol 169:122-135. https://doi.org/10.1016/j.agrformet. 2012.09.006

Qiu J (2008) The third pole. Nature 454(7203):393-396. https://doi.org/ $10.1038 / 454393 a$

Shang LY, Zhang Y, Lu SH, Wang SY (2015) Energy exchange of an alpine grassland on the eastern Qinghai-Tibetan Plateau. Sci Bull 60(4):435-446. https://doi.org/10.1007/s11434-014-0685-8

Wang J, Wang W, Liu S, Ma M, Li X (2009) The problems of surface energy balance closure-an overview and case study. Adv Earth Science 24(7):705-713

Wang K, Zhang T, Zhong X (2015) Changes in the timing and duration of the near-surface soil freeze/thaw status from 1956 to 2006 across China. Cryosphere 9(3):1321-1331. https://doi.org/10.5194/tc-9-1321-2015

Webster PJ (1987) The variable and interactive monsoon. Monsoon

Wilson K, Goldstein A, Falge E, Aubinet M, Baldocchi D, Berbigier P, Bernhofer C, Ceulemans R, Dolman H, Field C, Grelle A, Ibrom A, Law BE, Kowalski A, Meyers T, Moncrieff J, Monson R, Oechel W, Tenhunen J, Valentini R, Verma S (2002) Energy balance closure at FLUXNET sites. Agric For Meteorol 113(1-4):223-243. https://doi. org/10.1016/S0168-1923(02)00109-0

Wu Q, Zhang T, Liu Y (2012) Thermal state of the active layer and permafrost along the Qinghai-Xizang (Tibet) railway from 2006 to 2010. Cryosphere 6(3):607-612. https://doi.org/10.5194/tc-6-607-2012

Xian X, Jian G, Han B, Sun Q, Liu L (2009) The effect of climate warming and permafrost thaw on desertification in the QinghaiTibetan Plateau. Geomorphology 108(3):182-190

Yang MX, Yao TD, Gou XH, Koike T, He YQ (2003) The soil moisture distribution, thawing-freezing processes and their effects on the seasonal transition on the Qinghai-Xizang (Tibetan) plateau. J Asian Earth Sci 21(5):457-465. https://doi.org/10.1016/S1367-9120(02) 00069-X

Yang MX, Yao TD, Gou XH, Hirose N, Fujii HY, Hao LS, Levia DF (2007) Diurnal freeze/thaw cycles of the ground surface on the Tibetan Plateau. Chin Sci Bull 52(1):136-139. https://doi.org/10. 1007/s11434-007-0004-8

Yao JM, Zhao L, Gu LL, Qiao YP, Jiao KQ (2011) The surface energy budget in the permafrost region of the Tibetan Plateau. Atmos Res 102(4):394-407. https://doi.org/10.1016/j.atmosres.2011.09.001

Ye M, Qin N, Bai A, Li J, Li Y, Zhao Y (2015) Variation of summer maximum air temperature in Yellow River source region from 1618 to 2009. J Chengdu University Information Technol 30(4):385-389

Zhao L, Wu QB, Marchenko SS, Sharkhuu N (2010) Thermal state of permafrost and active layer in Central Asia during the international polar year. Permafrost Periglac 21(2):198-207. https://doi.org/10. 1002/ppp.688

Zheng J, Yin Y, Li B (2010) A new scheme for climate regionalization in China. Acta Geograph Sin 65(1):3-12

Zou D, Zhao L, Sheng Y, Chen J, Hu G, Wu T, Wu J, Xie C, Wu X, Pang Q, Wang W, du E, Li W, Liu G, Li J, Qin Y, Qiao Y, Wang Z, Shi J, Cheng G (2017) A new map of permafrost distribution on the Tibetan Plateau. Cryosphere 11(6):2527-2542. https://doi.org/10. 5194/tc-11-2527-2017

Publisher's note Springer Nature remains neutral with regard to jurisdictional claims in published maps and institutional affiliations. 